\title{
Reliability and validity of the Antioch Child Hygiene Scale: A scale development study
}

\author{
Ebru Turhan ${ }^{1 *}$, Tacettin Inandi²
}

'Research and Development Unit, Provincial Directorate of Public Health, Izmir, Turkey, ${ }^{2}$ Department of Public Health, Faculty of Medicine, Mustafa Kemal University, Antakya, Hatay, Turkey

\begin{abstract}
Introduction: Personal hygiene is one of the most important determinants of health. A scale of personal hygiene is a useful tool to evaluate effects of health care interventions. The aim of this study was to develop a new, reliable, and valid measurement scale which can be used to evaluate the hygiene status of children, as well as the effects of the interventions.

Methods: A total of 248 students and their parents, from Hatay Province in Turkey, participated in this school-based, cross-sectional study. An item pool was created for the Antioch Child Hygiene Scale (ACHS). Same questions were asked both for children (ACHS-C) and parents (ACHS-P) Data were collected in September 2013. Face validity, Cronbach's alpha, split-half, test-retest, factor analysis, and parallel form reliability were determined for the ACHS.
\end{abstract}

Results: Twelve items that showed a weak correlation were removed from the ACHS. The mean score (standard deviation) was $159.4 \pm 9.2$ for ACHS-C and $152.2 \pm 16.9$ for ACHS-P. Cronbach's alpha for ACHS-C was 0.82 in the first test and 0.87 in the retest. Cronbach's alpha for ACHS-P was 0.91 in the first test and 0.94 in the retest. Split-half correlation was 0.59 for ACHS-C and 0.75 for ACHS-P. Correlation between pre-test and post-test scores was 0.54 for ACHS-C and 0.64 for ACHS-P $(p<0.001)$. In the principle component analysis, (Eigen value was taken greater than 1), 20 components for ACHS-C and 13 components for ACHS-P were extracted.

Conclusions: Although both ACHS forms (i.e., ACHS-C and ACHS-P) were reliable in assessing the hygiene status of children, the reliability was higher for ACHS-P. In addition, validity should be improved in both forms of the ACHS. Nevertheless, both scales can be used to assess the hygiene status in school children.

Keywords: Hygiene; child; scale development; reliability; validity

\footnotetext{
*Corresponding author: Ebru Turhan, Research and Development Unit, Provincial Directorate of Public Health, Zubeyde Hanim Street,100, Karsiyaka, Izmır, Turkey. Phone: 0505 5602768. E-mail: turhanebru1@gmail.com
}

Submitted: 27 July 2016/Accepted: 10 December 2016

DOI: https://doi.org/10.17532/jhsci.2016.297

UNIVERSITY OF SARAJEVO FACULTY OF HEALTH STUDIES

\section{INTRODUCTION}

Hygiene can be defined as practices associated with maintaining good health and cleanliness habits. The term hygiene encompasses different measures and practices, including: Sanitary practices, preventive medicine and prevention of illness, practice, study 
and maintenance of health. It is usually divided into the following fields: Personal hygiene, domestic hygiene, food hygiene, and industrial hygiene (1). Personal hygiene is the practice of self-care, including bathing and grooming. Additionally, self-care includes care of the skin, hair, nails, mouth, teeth, eyes, ears, nasal cavities, and perineal and genital areas. In this study, the term hygiene refers to healthy and cleanliness habits and maintaining personal hygiene.

Numerous factors influence personal hygiene practices, including development stages, cultural background, socioeconomic status, religion, personal habits, and individual health status. Good personal hygiene is essential for good health and childhood may be the most appropriate period for learning these practices.

Several tools for evaluating health promotion in schools exist, and they analyze variables such as school environment, health education, activity programs, nutrition services, health services, counseling, and social services. One of these tools is the School Health Index (SHI) developed by Centers for Disease Control and Prevention. It is a self-assessment and planning tool that schools can use to improve their health and safety policies and programs (2).

The main focus of health promotion in schools is improving student health. Thus, it is necessary to obtain information on student attitude toward health. In addition, we need a valid and standardized tool to evaluate the effects of interventions in improving hygiene practices of children. In this context, a scale is also necessary to compare hygiene levels of the students by place and time.

Developing a reliable and valid scale is not easy mainly due to two reasons. Firstly, children have different capabilities at different ages. Secondly, hygiene is a broad term, as described above. Nevertheless, by reducing age range and using a multi-item scale it may be possible to develop measurement tools for the assessment of personal hygiene and practices in children. A multi-item scale is necessary because of a number of factors that are associated with personal hygiene, including cleanliness, sleep, nutrition, wearing, environment, and general habits. Narrowing age range is important because skills, behaviour, and attitudes related to hygiene differ between different age groups of children. Our sample included fourth and fifth year students in primary school due to their reading and writing abilities.

The aim of this study was to develop a new, valid, and reliable measurement scale that can be used to evaluate the hygiene status of children as well as the effects of the interventions.

\section{METHODS}

\section{Study population and sample}

In 2013, four primary schools were randomly selected and each school was from a different socioeconomic region (low, middle, good, and high) in Hatay Province, Turkey. From each school, two classes (fourth and fifth grades) were randomly selected, and all the students from the selected classes, as well as their parents, were included in the study. Informed consent was obtained from all the parents and the local Ethic Committee approved the study. The final sample included a total of 248 students and their parents.

\section{Items}

An item pool that included 71 items was created for the Antioch Child Hygiene Scale (ACHS) (3). The same items were designed for both, child (ACHS-C) and parent (ACHS-P) forms. This scale includes information on healthy life, oral and dental health, nutrition, sleep, hand, face and body hygiene, environment, and wearing. All items were Likert type questions with three choices (4). The three options were arranged in the same order: " 1 - Yes, always", " 2 - Sometimes", and " 3 - No, never". In the negative questions, 3 and 1 were replaced each other. A higher score indicated better hygiene practice.

\section{Data collection}

The data were collected in September 2013 from the children, in their classrooms. Simple instructions and a sample question were provided at the beginning of the questionnaires. Parents filled in the questionnaire at their home. For the retest, 53 children and their parents filled in the questionnaire again, after two weeks. 


\section{Statistical analysis}

Face validity of the scale was performed by interviewing 45 physicians and academics. Cronbach's alpha, split-half, and test-retest were tested to evaluate the reliability of both ACHS forms. Factor analysis was used for determining structural validity, and parallel form reliability was evaluated by correlating the two ACHS forms.

\section{RESULTS}

\section{Descriptive statistics}

On average, the students filled in the questionnaire in 25 minutes and it took less time for the parents to complete the questionnaire.

Table 1 shows the socio-demographic characteristics of the students. Out of 248 students, $42.3 \%$ were male, and $57.7 \%$ were female; $46.8 \%$ were in the fourth grade while $53.2 \%$ were in the fifth grade. The mean age ( \pm standard deviation $[S D]$ ) of the children was $10.5 \pm 0.6$. With regard to the type of family, $14.4 \%$ were extended families, and $85.6 \%$ were nuclear families.

Analysis of the parent education level showed that more than half of the parents were primary school graduates, while $9.5 \%$ of the mothers and $3.4 \%$ of the fathers were illiterate.

The mean scores of ACHS-C and ACHS-P with regard to the age and gender of the participants are presented in Table 2 . There were no statistically significant differences in the mean scores of the two ACHS forms with regard to the age. On contrary, a statistically significant difference was observed in the mean ACHS scores with regard to the gender; Female students had higher scores than male students in the ACHS-C and ACHS-P. $(p<0.01)$.

\section{Reliability results}

According to the item analysis, 12 items showed a weak correlation and thus were removed, while 59 items were used in the scale. Cronbach's alpha values and means ( \pm SDs) of both forms are presented in Table 3. The mean score $( \pm \mathrm{SD})$ for ACHS-C was $159.4 \pm 9.2($ minimum $=127$ and maximum $=176)$ and $152.2 \pm 16.9$ (minimum $=100$ and maximum $=186$ ) for ACHS-P. Cronbach's alpha values
TABLE 1. Socio-demographic characteristics of the students

\begin{tabular}{|c|c|c|}
\hline Parameters & $\mathrm{n}$ & $\%$ \\
\hline \multicolumn{3}{|l|}{ Gender } \\
\hline Male & 105 & 42.3 \\
\hline Female & 143 & 57.7 \\
\hline Total & 248 & 100.0 \\
\hline \multicolumn{3}{|l|}{ Classes } \\
\hline Fourth grade & 116 & 46.8 \\
\hline Fifth grade & 132 & 53.2 \\
\hline Total & 210 & 100.0 \\
\hline \multicolumn{3}{|c|}{ Education level of mothers } \\
\hline Illiterate & 20 & 9.5 \\
\hline Primary school & 128 & 61.0 \\
\hline Secondary school & 16 & 7.6 \\
\hline High school & 30 & 14.3 \\
\hline University & 16 & 7.6 \\
\hline Total & 205 & 100.0 \\
\hline \multicolumn{3}{|c|}{ Education level of fathers } \\
\hline Illiterate & 7 & 3.4 \\
\hline Primary school & 111 & 54.1 \\
\hline Secondary school & 29 & 14.1 \\
\hline High school & 29 & 14.1 \\
\hline University & 29 & 14.1 \\
\hline Total & 201 & 100.0 \\
\hline \multicolumn{3}{|l|}{ Family type } \\
\hline Extended & 29 & 14.4 \\
\hline Nuclear & 172 & 85.6 \\
\hline Students & Mean & SD \\
\hline Age (years) & 10.5 & 0.6 \\
\hline Weight (kilograms) & 32.4 & 5.4 \\
\hline Height (centimeters) & 138.8 & 7.9 \\
\hline
\end{tabular}

varied between 0.82 and 0.94. Cronbach's alpha for ACHS-C was 0.82 in the first test and 0.87 in the retest. Cronbach's alpha for ACHS-P was 0.91 in the first test and 0.94 in the retest.

Split-half correlation was 0.59 for ACHS-C and 0.75 for ACHS-P. The correlation between pre-test and post-test scores for ACHS-C was 0.54 and 0.64 for ACHS-P $(p<0.001)$.

ACHS-P and ACHS-C were split up into seven subgroups: Oral and dental, sleep, body clean, environmental sensitivity, nutrition and food, and wearing group. The scores were calculated for each group, and the correlation matrix for ACHS-C is presented in Table 4. All subgroups showed a positive correlation between each other. The strongest correlation 
TABLE 2. Mean ACHS scores by age and gender

\begin{tabular}{lcc}
\hline Age & ACHS-C & ACHS-P \\
\hline 10 & 159.7 & 151.4 \\
Mean & 115 & 115 \\
$n$ & 9.7 & 17.9 \\
SD & & \\
11 & 159.4 & 152.9 \\
Mean & 126 & 126 \\
$n$ & 8.7 & 16.41 \\
SD & & \\
Mann Whitney U test & $p=0.56$ & $p=0.72$ \\
Gender & & \\
Male & & \\
Mean & 156.9 & 147.6 \\
$n$ & 105 & 105 \\
SD & 9.6 & 18.2 \\
Female & & \\
Mean & 161.4 & 155.5 \\
$n$ & 142 & 142 \\
SD & 8.3 & 15.2 \\
Mann Whitney U test & & \\
Total & $p<0.0001$ & 152.2 \\
Mean & 159.5 & 241 \\
$n$ & 241 & 17.1 \\
SD & 9.2 & \\
\hline ACHS-P:Anto & & \\
& &
\end{tabular}

ACHS-P: Antioch child hygiene scale-parents;

ACHS-C: Antioch child hygiene scale-children; SD: Standard deviation

TABLE 3. Cronbach's alpha values and means (standard deviations [SDs]) for ACHS-C and ACHS-P

\begin{tabular}{lccc}
\hline & Mean & SD & Cronbach's alpha \\
\hline Child & 159.4 & 9.2 & 0.82 \\
Parent & 152.2 & 16.9 & 0.91 \\
Child retest & 189.1 & 13.5 & 0.87 \\
Parent retest & 178.3 & 21.3 & 0.94 \\
\hline
\end{tabular}

ACHS-P: Antioch child hygiene scale-parents;

ACHS-C: Antioch child hygiene scale-children; SD: Standard deviation

$(\mathrm{r}=0.43)$ was observed between sleep and nutrition and food groups, while the weakest correlation $(\mathrm{r}=0.13)$ was observed between sleep and wearing groups. The correlation matrix of the subgroups for ACHS-P is presented in Table 5. The strongest correlation $(\mathrm{r}=0.84)$ was observed between body clean and wearing groups, while the weakest correlation $(\mathrm{r}=0.37)$ was observed between sleep and oral and dental health groups. The correlations between the subgroups of ACHS-P were stronger than the correlations between the sub-groups of ACHS-C.

\section{Validity results}

According to the results of face validity, all the medical doctors and academicians agreed that the 71 items were related to children hygiene.

In order to evaluate the construct validity of the scales, factor analyses were performed. In the principle component analysis, 20 components were extracted. These compents consisted of $64 \%$ of the variance in the ACHS-C. In the ACHC-P, 13 components were extracted and this 13 components consisted $65.6 \%$ of the variance.

\section{Discriminative features}

Statistically significant differences between the mean scores of both forms were observed with regard to the gender $(p<0.05)$. However, the difference by age was not significant $(p>0.05)$.

Child form and parent form of the scale were significantly correlated each other, and this indicate that scale had a good parallel form validity. The correlation matrix of the subgroups of both ACHS forms is presented in Table 6 . In a total of 64 cells, correlations were significant in 53 cells (82.8), while they were not significant in 11 cells (17.2). On the other hand, six of seven subgroups were significantly correlated between the two ACHS forms, and only habits scores were not correlated. The correlation between the total scores of both ACHS forms was 0.48 .

\section{DISCUSSION}

Hygiene is a very broad term, and to effectively evaluate hygiene practice numerous items should be included in a scale. It is generally accepted that better results are obtained with larger item pools (3). Also, the characteristics of participants should be considered when using these scales. In this study, most of the students were 10 or 11 years old, and they probably could not respond to a longer questionnaire. Therefore, we did not create a large item pool and 71 questions about individual hygiene 
TABLE 4. Correlation matrix of subgroups and total scores for ACHS-C

\begin{tabular}{lccccccc}
\hline Total and subgroups & Total & Oral and dental & Sleep & Body clean & $\begin{array}{c}\text { Environmental } \\
\text { sensitivity }\end{array}$ & $\begin{array}{c}\text { Nutrition } \\
\text { and food }\end{array}$ & Wearing \\
\hline Oral and dental & $0.46^{* *}$ & & & & & \\
Sleep & $0.69^{* *}$ & $0.30^{* *}$ & & & & & \\
Body clean & $0.63^{* *}$ & $0.32^{* *}$ & $0.29^{* *}$ & & & & \\
Environmental sensitivity & $0.55^{* *}$ & $0.19^{* *}$ & $0.32^{* *}$ & $0.32^{* *}$ & & & \\
Nutrition and food & $0.87^{* *}$ & $0.26^{* *}$ & $0.43^{* *}$ & $0.42^{* *}$ & $0.32^{* *}$ & & \\
Wearing & $0.37^{* *}$ & $0.18^{* *}$ & $0.13^{* *}$ & $0.20^{* *}$ & $0.28^{* *}$ & $0.17^{* *}$ & \\
Habits & $0.54^{* *}$ & $0.27^{* *}$ & $0.22^{* *}$ & $0.34^{* *}$ & $0.24^{* *}$ & $0.39^{* *}$ & $0.24^{* *}$ \\
\hline
\end{tabular}

${ }^{* *} p<0.01$; ACHS-C: Antioch child hygiene scale-children

TABLE 5. Correlation matrix of subgroups and total scores for ACHS-P

\begin{tabular}{lccccccc}
\hline & Total & Oral and dental & Sleep & Body clean & $\begin{array}{c}\text { Environmental sensitivity } \\
\text { Nutrition } \\
\text { and food }\end{array}$ & Wearing \\
\hline Oral and dental & $0.67^{* *}$ & & & & & & \\
Sleep & $0.66^{* *}$ & $0.37^{* *}$ & & & & & \\
Body clean & $0.86^{* *}$ & $0.62^{* *}$ & $0.48^{* *}$ & & & & \\
Environmental sensitivity & $0.84^{* *}$ & $0.63^{* *}$ & $0.46^{* *}$ & $0.78^{* *}$ & & & \\
Nutrition and food & $0.87^{* *}$ & $0.47^{* *}$ & $0.41^{* *}$ & $0.62^{* *}$ & $0.62^{* *}$ & & \\
Wearing & $0.83^{* *}$ & $0.60^{* *}$ & $0.50^{* *}$ & $0.84^{* *}$ & $0.70^{* *}$ & $0.61^{* *}$ & \\
Habits & $0.80^{* *}$ & $0.51^{* *}$ & $0.36^{* *}$ & $0.75^{* *}$ & $0.69^{* *}$ & $0.65^{* *}$ & $0.75^{* *}$ \\
\hline
\end{tabular}

${ }^{* *} p<0.01$; ACHS-P: Antioch child hygiene scale-parents

TABLE 6. Correlation matrix of subgroups and total scores for ACHS-P and ACHS-C

\begin{tabular}{lcccccccc}
\hline ACHS-C & \multicolumn{7}{c}{ ACHS-P } \\
\cline { 2 - 9 } & Total & $\begin{array}{c}\text { Oral and } \\
\text { dental }\end{array}$ & Sleep & Body clean & $\begin{array}{c}\text { Environmental } \\
\text { sensitivity }\end{array}$ & Nutrition and food & Wearing & Habits \\
\hline Total & $0.48^{* *}$ & $0.34^{* *}$ & $0.35^{* *}$ & $0.42^{* *}$ & $0.37^{* *}$ & $0.44^{* *}$ & $0.35^{* *}$ & $0.32^{* *}$ \\
Oral and dental & $0.11^{* *}$ & $0.22^{* *}$ & $0.13^{*}$ & $0.18^{* *}$ & $0.14^{*}$ & $0.15^{*}$ & 0.11 & 0.11 \\
Sleep & $0.33^{* *}$ & $0.24^{* *}$ & $0.38^{* *}$ & $0.23^{* *}$ & $0.23^{* *}$ & $0.29^{* *}$ & $0.18^{* *}$ & $0.19^{* *}$ \\
Body clean & $0.34^{* *}$ & $0.20^{* *}$ & $0.18^{* *}$ & $0.36^{* *}$ & $0.28^{* *}$ & $0.30^{* *}$ & $0.28^{* *}$ & $0.27^{* *}$ \\
Environmental sensitivity & $0.23^{* *}$ & $0.20^{* *}$ & $0.16^{*}$ & $0.21^{* *}$ & $0.22^{* *}$ & $0.17^{* *}$ & $0.19^{* *}$ & $0.16^{*}$ \\
Nutrition and food & $0.45^{* *}$ & $0.30^{* *}$ & $0.29^{* *}$ & $0.38^{* *}$ & $0.34^{* *}$ & $0.45^{* *}$ & $0.32^{* *}$ & $0.30^{* *}$ \\
Wearing & $0.16^{*}$ & 0.09 & 0.08 & $0.20^{* *}$ & 0.12 & 0.11 & $0.25^{* *}$ & $0.15^{*}$ \\
Habits & 0.16 & 0.16 & 0.09 & $0.22^{* *}$ & 0.11 & $0.13^{*}$ & $0.16^{*}$ & 0.10 \\
\hline
\end{tabular}

${ }^{* *} p<0.01$; ${ }^{*} p<0.05$; ACHS-P: Antioch child hygiene scale-parents; ACHS-C: Antiochchild hygiene scale-children

of a child were included. Some issues were asked twice in different questions. Furthermore, the items were constructed in a simple manner; very short sentences were used and the choices were limited to three options. Each item had a score between 1 and 3, and the total score ranged between 71 and 213. After the 12 items with a weak correlation were excluded, the minimum and maximum total scores were 59 and 177 , respectively.

\section{Reliability}

The purpose of reliability is to estimate error variance (5). Reliability refers to the consistency of a measure, and a test or tool is considered reliable if we get the same result in repeated measurements. Although it is not possible to exactly calculate the reliability, it can be estimated by different methods such as item analysis, internal consistency, Cronbach's alpha, split-half, test-retest, and parallel 
form reliability (6). We used item analysis, internal consistency, split-half method, and retest to estimate the reliability of ACHS-C and ACHS-P forms.

Internal consistency measures whether several items that propose to measure the same general construct produce similar scores, and it is based on the correlations between different items on the same test. Cronbach's alpha is usually used for measuring internal consistency, and is calculated from the pairwise correlations between items. Internal consistency ranges between zero and one (7). In this study, internal consistency for ACHS-C was very good and it was excellent for ACHS-P (3).

Split-half method is an alternative way of evaluating the reliability of a scale. There was a strong correlation between the two parts of ACHS-C and ACHS-P scales $(p<0.001)$. However, the correlation was higher for ACHS-P compared to ACHS-C.

Test-retest method is one of the easiest ways to estimate the reliability of a measurement tool. In this method, the same test is applied to the same sample at two different time points. This approach assumes that there is no substantial change between the two time points. The amount of time allowed between two measurements is important. The shorter the time gap, the higher the correlation; similarly, the longer the time gap, the lower the correlation. In this study, the time gap was 2 weeks, and the test-retest correlation was good for both ACHS forms $(p<0.001)$.

\section{Validity}

Validity is the extent to which a test measures what it claims to measure. Several types of validity exist: Predictive validity, concurrent validity, content validity, criterion-related validity, and construct validity (3). In this study, face validity and construct validity were used. A test has construct validity if it demonstrates an association between the test scores and the prediction of a theoretical trait. Face validity is a property of a test intended to measure something, and it can be said to have face validity if a test appears like it is going to measure what it is supposed to measure. With regard to face validity, 45 physicians and academicians in medical faculty approved all the items in the pool.
Construct validity analyzes whether a scale measures or correlates with the theoretical psychological construct. In the factor analysis of the items, 20 components that include $64.0 \%$ of total variance in the child form were created, and these were more than our 7 theoretical factors. With regard to parent form, 13 components were created and their factor load was $65.6 \%$. Extracted factors from the parent forms were less and factor load was higher than the extracted factors from the child form. Factor analysis confirmed that ACHS-P has more validity than ACHS-C with regard to construct validity. However, sub-domains of the both scales need to be improved.

The significant differences in the total scores according to the gender suggest that gender has a discriminative role. On the other hand, the differences in the total scores according to the age were not significant, and this may be due to the narrow age range of the subjects.

\section{CONCLUSION}

Both forms of the ACHS have shown to be reliable, but the reliability was higher for ACHS-P than for ACHS-C. Validity of both scales should be improved, and further studies are required in this area.

\section{CONFLICT OF INTEREST}

The authors declare no conflict of interest.

\section{REFERENCES}

1. Aunger R, Greenland K, Ploubidis G, Schmidt W, Oxford J, Curtis V. The Determinants of Reported Personal and Household Hygiene Behaviour: A Multi-Country Study. PloS one. 2016 Aug 19;11(8):e0159551.

2. Centers for Disease Control and Prevention. School Health Index: A self assessment and Planning Guide. Elementary school version. Atlanta, Georgia. 2012.

3. DeVellis RF. Scale Development: Theory and Applications (Applied Social Research Methods, Volume 26). $2^{\text {nd }}$ ed. California: Sage Publications; 2003.

4. Sullivan GM, Artino Jr AR. Analyzing and interpreting data from Likert-type scales. Journal of graduate medical education. 2013 Dec;5(4):541-2.

5. Groth-Marnat G. Handbook of psychological assessment. $4^{\text {th }}$ ed. Hoboken, New Jersey: John Wiley \& Sons, Inc.; 2003.

6. Carmines EG, Zeller RA. Reliability and validity assessment. $1^{\text {st }}$ ed. California: Sage Publications; 1979.

https://doi.org/10.4135/9781412985642.

7. Cronbach LJ. Coefficient alpha and the internal structure of tests. Psychometrika 1951;16(3):297-334.

https://doi.org/10.1007/BF02310555. 